\title{
The U.S. Occupational Structure: A Social Network Approach
}

\author{
Andrés Villarreal
}

University of Maryland-College Park

\begin{abstract}
We propose a new approach to study the structure of occupational labor markets that relies on social network analysis techniques. Highly detailed transition matrices are constructed based on changes in individual workers' occupations over successive months of the Current Population Survey rotating panels. The resulting short-term transition matrices provide snapshots of all occupational movements in the U.S. labor market at different points in time and for different sociodemographic groups. We find a significant increase in occupational mobility and in the diversity of occupational destinations for working men over the past two decades. The occupational networks for black and Hispanic men exhibit a high overall density of ties resulting from a high probability of movement among a limited set of occupations. Upward status mobility also increased during the time period studied, although there are large differences by race and ethnicity and educational attainment. Finally, factional analysis is proposed as a novel way to explore labor market segmentation. Results reveal a highly segmented occupational network in which movement is concentrated within a limited number of occupations with markedly different levels of occupational status.
\end{abstract}

Keywords: occupational mobility; network analysis; labor market segmentation

Citation: Villarreal, Andrés. 2020. "The U.S. Occupational Structure: A Social Network Approach." Sociological Science 7: 187-221.

Received: November 22, 2019

Accepted: March 31, 2020

Published: May 18, 2020

Editor(s): Jesper Sørensen, Kim Weeden

DOI: $10.15195 /$ v7.a8

Copyright: (C) 2020 The Author(s). This open-access article has been published under a Creative Commons Attribution License, which allows unrestricted use, distribution and reproduction, in any form, as long as the original author and source have been credited. @()
CCUPATIOns have long been central to sociological research on labor markets and social stratification. The occupation in which individuals are employed is generally considered an important predictor of their earnings and a good measure of their social standing (Blau and Duncan 1967; Hauser and Warren 1997; Mouw and Kalleberg 2010; Weeden and Grusky 2005). Research on gender and racial inequality, for example, has found that the sorting of workers across occupations accounts for a large share of the gender and racial wage gaps (Petersen and Morgan 1995; Tomaskovic-Devey 1993). Occupational differences in wages also help explain the overall growth in inequality since the 1980s (Mouw and Kalleberg 2010). Not only are occupations important predictors of economic outcomes; they are also associated with differences in beliefs, attitudes, and lifestyles in ways that make them appropriate units for class analysis (Weeden and Grusky 2005).

Given the importance of occupations for individuals' life chances, it is not surprising that sociologists have been deeply concerned with the extent to which workers are able to move between occupations. Such movements are restricted by numerous structural factors, leading to a segmentation of the labor market along occupational lines (Althauser 1989; Kalleberg and Mouw 2018; Rosenfeld 1992). Researchers have in fact argued that occupations constitute relatively separate labor markets with their own supply and demand of workers (Doeringer and Piore 1971; Stolzenberg 1975). Employers seeking to hire an accountant, for example, are unlikely to consider an applicant whose prior work has not been in accounting or some related field. That is because occupations such as accounting often exclude 
workers without proper credentials. More generally, social closure practices, which may also include licensing, voluntary certification, and unionization in addition to credentialing, restrict the labor supply to particular occupations, thereby raising the earnings of workers in those occupations (Grusky and Sørensen 1998; Weeden 2002). Although previous studies have convincingly demonstrated that the labor market is segmented along occupational lines, we know surprisingly little about how it is segmented, that is, among which occupations workers are most likely to move. New methodological techniques are required to further uncover the underlying structure of the occupational labor market.

Research on inter- and intragenerational mobility has, of course, also been concerned with the extent to which individuals are able to move between occupations, specifically to those deemed to have higher social status. Individuals' ability to move to higher-status occupations over their own lifetimes and relative to their parents is often considered a key indicator of equality of opportunities (Blau and Duncan 1967; Breen and Jonsson 2005; Erikson and Goldthorpe 1992; Torche 2015a). In this line of research, occupations are usually ranked along a single-dimensional scale of social status or grouped into highly aggregated occupational categories meant to approximate social classes (Torche 2015b). Assigning an index of social status to occupations allows researchers to employ linear regression techniques to analyze occupational mobility, whereas grouping occupations into broad categories enables the use of categorical data analysis to examine occupational contingency tables (Hauser 1978; Hout 1983). Both of these methodological strategies have yielded important insights regarding the movement of workers to occupations of different social standing but provide an incomplete picture of the overall structure of the occupational labor market. Traditional modeling strategies also often impose a specific structure to the pattern of movement across occupations (Sakamoto and Wang 2019).

In this article we propose an alternative approach to study the structure of the U.S. occupational labor market that relies on tools developed for the analysis of social networks. Information regarding the movement of workers across occupations is obtained from the Current Population Survey (CPS), a nationally representative survey with a rotating panel format. Changes in respondents' occupation over successive months allow us to construct highly detailed transition matrices that are representative of all occupational movements. The resulting short-term transition matrices provide snapshots of the structure of the U.S. labor market at successive points in time. We also examine differences in the evolution of the occupational structure for different sociodemographic groups by constructing separate matrices for subgroups of the adult population.

This network analysis approach allows us to explore aspects of the U.S. occupational labor market that are not evident with standard methods used to study mobility. For example, measures of network density can be used to examine the interconnectedness of occupations, that is, the amount and diversity of occupational movements experienced by workers in the entire labor market and within subgroups of occupations. We are able to consider paths through the occupational network involving multiple steps to determine which occupations can be reached by workers over successive job changes. We can assess the level of occupational status 
mobility in the labor market at a point in time and for different sociodemographic groups by measuring the level of connectivity and geodesic distance between lowand high-status occupations. Finally, techniques developed to identify subgroups within a social network can be used to analyze occupational segmentation. Such techniques tell us whether job changes are concentrated among certain occupations without imposing a specific structure to the pattern of occupational movements.

An additional advantage of the network analysis approach we propose is that it can be implemented with readily available data from rotating panel surveys such as the CPS. Our approach may also be applied to other national contexts as many countries regularly conduct employment surveys with similar data structures (e.g., INEGI 2005; Office for National Statistics 2019; Statistics Canada 2009). Prior strategies for the study of intragenerational mobility often rely on longitudinal data that follow specific cohorts over the course of their working lives, or surveys containing retrospective information (e.g., Kronberg 2013; Sørensen 1975; Sørensen and Grusky 1996; Stier and Grusky 1990). Such data sources are scarcer. Also, because multiple waves of the CPS can be appended, the sample sizes obtained are large enough to examine workers' movements using highly detailed occupational categories.

In the following sections we first motivate the research questions addressed by the network analysis approach. We briefly review the literature on occupational mobility and occupational labor market segmentation to derive some basic expectations that guide the empirical analysis. We then define occupational networks and describe how network analysis techniques can help us better understand the structure of occupational labor markets.

\section{Occupational Mobility}

Occupations play a central role in sociological theories of stratification. An underlying assumption of these theories is that there is something durable about occupations that affect individuals' life chances beyond the characteristics of the individuals who work in them. As noted earlier, occupations confer status and are important predictors of earnings (Weeden and Grusky 2005; Mouw and Kalleberg 2010). The ability to move between occupations is therefore often considered an important measure of the opportunities available to workers. However, widespread occupational movement may also reflect economic downturns (Jarvis and Song 2017).

Recent research has documented a consistent increase in occupational mobility over time (Jarvis and Song 2017; Kambourov and Manovskii 2008; Longui and Brynin 2010; Parrado, Caner, and Wolff 2007). Using data from the Panel Study of Income Dynamics and two-digit occupational codes, Kambourov and Manovskii (2008) find that the annual rate at which employed individuals change occupations rose from 12 to 17 percent between 1968 and 1997. Because occupation-specific human capital is highly rewarded and generally accrues with longer tenure in an occupation, moving to new occupations may actually result in lower wages (Kambourov and Manovskii 2008, 2009). Thus, rather than a measure of greater eco- 
nomic opportunities, higher occupational mobility may also reflect worse economic outcomes (Hollister 2012).

Researchers also find that occupational mobility varies across sociodemographic groups. As might be expected, older workers, who generally have longer tenure in an occupation and therefore more to lose by moving, experience fewer occupational transitions (Hollister 2012; Moscarini and Vella 2008; Parrado et al. 2007). More educated workers have also been found to have lower occupational mobility (Kambourov and Manovskii 2008; Moscarini and Vella 2008; Parrado et al. 2007). Less is known about patterns across racial groups, although Parrado et al. (2007) report no significant differences in occupational mobility between white and nonwhite men during the 1980s and early 1990s. Finally, the rate at which workers experience occupational changes also depends on macroeconomic factors. Kambourov and Manovskii (2008) find that occupational mobility is mildly procyclical. By contrast, DiPrete and Nonnemaker (1997) find that occupational mobility increases with industrial contraction.

In the analysis below we will use network analysis techniques to estimate occupational mobility over the past two decades for workers of different race and ethnicity and level of education. The analysis updates trends in occupational mobility through 2016. More importantly, as described below, network analysis tools allow us to analyze new aspects of occupational mobility beyond the average rate at which workers change occupations. For example, we are able to measure the diversity in occupational movements occurring in the labor market using detailed occupational categories. We can also examine movements involving multiple occupational transitions.

\section{Intragenerational Mobility}

Sociologists have not only been interested in studying the movement of workers across all occupations in the labor market but have been especially concerned with the extent to which workers are able to move vertically within a hierarchy of occupations. Individuals' ability to move to higher-status occupations relative to their parents or over their own lifetimes is considered a measure of equality in opportunities (Blau and Duncan 1967; Erikson and Goldthorpe 1992; Torche 2015b). Although researchers have more often focused on occupational mobility across generations, there is an increasing interest in workers' occupational advancement over the course of their own lives (Jarvis and Song 2017; Kalleberg and Mouw 2018).

One traditional approach to the study of occupational status mobility involves the analysis of two-way contingency tables using log-linear models (Hauser 1978; Hout 1983). The rows and columns in such tables represent the occupational groups of origin and destination, respectively. Although log-linear models have yielded important insights into the patterns of inter- and intragenerational mobility, they have some limitations (Sakamoto and Wang 2019). Log-linear models often impose a specific structure to occupational movements that may not always be warranted. Contingency tables used in log-linear models are also typically based on highly aggregated occupational groups that are meant to capture broad social classes, although some recent studies use more disaggregated occupational categories 
(Jarvis and Song 2017; Jonsson et al. 2009; Sørensen and Grusky 1996). In a recent study, Jarvis and Song (2017) use log-linear models to examine intragenerational occupational mobility at different levels of aggregation over the span of several decades. Their study is one of the first to estimate changes in intragenerational occupational mobility over time. Jarvis and Song (2017) find an overall increase in occupational mobility at most levels of aggregation since the early 1990s. They suggest that the increased mobility of workers over the span of their careers may be counteracting the null or slightly negative trends in intergenerational mobility.

The methodological strategy for studying occupational status mobility introduced below also relies on an analysis of contingency tables constructed at different levels of aggregation, including highly detailed occupational categories. However, instead of applying log-linear models to analyze mobility patterns, we employ tools developed for the analysis of social networks. As described below, network analysis tools provide greater flexibility in the study of occupational status mobility. Treating short-term contingency tables for different years as social networks allows us to test changes in occupational mobility over time for workers of different sociodemographic backgrounds without imposing a particular structure to the underlying pattern of movements. We are also able to examine occupational status mobility over longer chains of occupational transitions. Traditional methods for analyzing occupational status mobility only consider changes in status resulting from single transitions. As described below, network analysis tools can help us explore the occupational status that workers may reach over multiple occupational transitions.

Whereas early work on intragenerational mobility relied on the application of log-linear models to analyze contingency tables (Blau and Duncan 1967; Featherman and Hauser 1978), more recent research has employed event history modeling using individuals' entire job histories (DiPrete and Nonnemaker 1997; Gerber 2002; Parrado 2005; Shin 2007; Yu 2010; Zhou, Tuma, and Moen 1997). This research has been made possible by the greater availability of panel surveys and one-time surveys collecting retrospective job histories both in the United States and other countries. Event history models provide many advantages over older methods based on the analysis of contingency tables. Instead of relying only on individuals' first and most recent occupations as early work on intragenerational mobility did, event history models allow researchers to track individual workers' job transitions during a large span of their working lives. However, longitudinal data sets are often limited to a few birth cohorts or have an insufficient number of cases to conduct analysis that is representative of detailed occupational categories. Estimates obtained from retrospective work histories may also be biased due to recall problems (Manzoni, Luijkx, and Muffels 2011).

\section{Labor Market Segmentation}

Given the importance of occupational mobility for individuals' economic conditions and social standing, sociologists have naturally been interested in understanding how occupational movement is restricted by structural features of the labor market (Rosenfeld 1992; Kalleberg and Mouw 2018). One significant barrier to occupational movement stems from the operation of internal labor markets (ILMs), broadly 
defined as clusters of jobs with a high degree of social closure in which workers are to some extent shielded from external competition, and in which workers are afforded opportunities for promotion with the acquisition of greater skills (Althauser 1989; Althauser and Kalleberg 1981; Doeringer and Piore 1971; Rosenfeld 1992). Although ILMs are more often thought to operate within firms, where they provide career ladders for some workers, they are also found within occupations (Althauser 1989; Doeringer and Piore 1971; Kalleberg and Mouw 2018:286). Through licensing, credentialing, and unionization, some occupations exhibit social closure thereby raising the earnings for individuals employed in them (Grusky and Sørensen 1998; Weeden 2002).

To the extent that they operate at the occupational level, ILMs will reduce the movement of workers between occupations or at least confine such movements to particular occupational clusters, leading to greater overall labor market segmentation. Occupations vary in the extent to which they comprise occupational internal labor markets (OILMs). For example, high-skilled professional occupations may exhibit greater social closure because they are more likely to require specific educational credentials and licenses (Weeden 2002:69-70). Although less studied, access to OILMs may also vary by race and ethnicity as minority workers are often left out of lucrative jobs with greater opportunities for career advancement (Baldi and McBrier 1997; Pomer 1986; Rosenfeld 1980; Wilson and Roscigno 2010).

Occupational movement is not only reduced by practices of social closure but also by a disincentive created by high returns to occupational tenure. As noted earlier, workers accumulate occupation-specific skills after working in a particular occupation for an extended period of time. These skills are highly rewarded but are often not directly transferable to other occupations (Kambourov and Manovskii 2009; Kwon and Milgrom 2014; Sullivan 2010). The high returns to occupational experience will reduce the incentive for individuals to change occupations or will restrict such changes to a cluster of occupations to which their skills are somewhat transferable. We may expect the rewards to occupational tenure to also vary by skill level and with the level of educational attainment required (Kambourov and Manovskii 2008). The higher returns to advanced skills in professional occupations may inhibit the movement of workers out of such occupations. Finally, broader economic changes affecting overall labor demand may alter the returns to occupational experience and therefore the extent of occupational mobility overall. In a tighter labor market, employers may be more willing to hire workers from other occupations and absorb the cost of training them to perform new tasks.

In sum, the extent of movement of workers across groups of occupations and the consequent segmentation of the labor market are affected by numerous factors. Insofar as they operate in an economy, OILMs will restrict occupational movement by processes of social closure. Higher returns to occupational experience will also create a disincentive for workers to move, leading to greater occupational segmentation. Occupational movement is expected to vary with changes in economic conditions over time and for workers of different race, ethnicity, and skill level. Yet, despite the importance of occupational segmentation in sociological accounts of labor market dynamics, we lack appropriate methods for exploring how labor markets are segmented. In the analysis below we introduce a novel way to mea- 
sure labor market segmentation using techniques developed for the identification of network factions. As explained in the methodological section below, factional analysis allows us to detect clusters of occupations among which workers move relatively freely but across which workers are not easily able to move, thus closely resembling OILMs.

\section{The Occupational Labor Market as a Social Network}

Modeling the occupational labor market as a social network requires us to think of occupations, rather than individuals, as the units of analysis. Each occupation constitutes a node in a network, and the strength of the tie between nodes is proportional to the number of workers who move between occupations over a discrete period of time. In standard sociometric notation, the relation between nodes may be expressed as a matrix $\mathbf{X}$ with $n$ rows and $n$ columns, where $n$ is the number of nodes or occupations. As explained below, for the analysis of social mobility it is useful to define each element $x_{i j}$ as the proportion of workers employed in occupation $i$ who move to occupation $j$ during a single time interval. Defined in this way, $x_{i j}$ is an estimate of the probability that a worker in occupation $i$ will make that transition.

In social network terminology, the occupational network is a valued network because the strength of a tie between nodes may take on a value along a scale (in this case from 0 to 1 ), rather than a binary value based on whether a tie between two nodes exists. However, for some of the analysis below it will be useful to dichotomize the value of a tie between two occupations. For such an analysis, ties between two occupations will sometimes be restricted to only those that meet a certain probability threshold to minimize the influence that very rare occupational transitions may have on estimates of network connectivity and social mobility. The occupational network is also a directed network because the probability of moving from occupation $i$ to occupation $j$ need not be the same as the probability of moving from occupation $j$ to occupation $i{ }^{1}$ Finally, the occupational network is nonreflexive in that it does not allow self-ties $\left(x_{i j}=0\right.$ if $\left.i=j\right) .^{2}$

In the three subsections below we introduce multiple techniques for the analysis of social networks and describe how they can be used to analyze the three aspects of occupational labor markets discussed in the previous sections: occupational mobility and connectivity, intragenerational status mobility, and occupational labor market segmentation.

\section{Network Cohesion: Measuring Occupational Mobility and Connectivity}

The concept of cohesion in network analysis captures the extent to which nodes in a social network are interconnected (Borgatti, Everett, and Johnson 2013). In networks in which each node is an individual and each link represents the strength of a social tie between individuals, network cohesion may reflect the extent to which information or influence may travel throughout the network (Moody and Coleman 2015). In an occupational network, however, greater cohesion implies greater 
movement between occupations. A more cohesive network is one in which workers have greater occupational options as they are able to move to other occupations either directly or over the course of multiple occupational transitions depending on the specific measure of cohesion used. Several measures of network cohesion have been developed and will be applied to the occupational network data below. Each measure provides different information about the extent of occupational movement across the labor market.

Density. The simplest measure of cohesion in a network is its density. In a binary network, density is simply defined as the total number of direct ties in the network as a proportion of all possible ties. Excluding self-ties, the total number of possible ties in a directed network is $n(n-1)$, where $n$ is the number of nodes. Thus, density may be expressed as

$$
\text { density }=\frac{\sum_{i=1}^{n} \sum_{j=1}^{n} x_{i j}}{n(n-1)},
$$

where $x_{i j}$ in this case is a binary variable indicating whether a tie exists. The density of an occupational network can be interpreted as the probability that a transition between two randomly chosen occupations exists. A higher density indicates a more fluid occupational structure.

It is important to note that the density of the dichotomized occupational network provides different information than more customary measures of mobility, usually defined as the probability that a worker will change occupations. The density of binary networks captures the diversity in occupational transitions. Thus, an occupational labor market could potentially exhibit a high degree of mobility and a low network density when binary ties are used if all movements are concentrated among a few occupations.

Density can also be estimated for valued networks using the same formula. The density of a network with valued ties measures the average strength across all possible ties. For the occupational network in which each tie $x_{i j}$ represents the probability that a worker in occupation $i$ will move to occupation $j$, network density will measure the average probability that an occupational transition will occur. When applied to valued networks, density is in fact proportional to a standard measure of mobility defined as the average probability that a worker will change occupations. ${ }^{3}$ Thus, although they are computed in similar ways, the densities of the valued and binary occupational networks have substantively different meanings. Whereas the density of the binary network captures the diversity in occupational transitions, which we hereafter refer to as occupational connectivity, the density of the valued network captures the average probability of an occupational transition, which we refer to as occupational mobility.

Connectedness. As defined above, network density can be computed based solely on information regarding the occupations with which each particular occupation is directly connected by the movement of workers over a single time period. Such analysis ignores the full network in which an occupational node is embedded. When studying an occupational network, it is important to consider the occupations that workers can reach over multiple transitions because many workers will change occupations more than once during their lifetimes (e.g., Fuller 2008; Shaw 1987). Several measures of cohesion allow us to consider occupations that can be reached 
over multiple steps. ${ }^{4}$ First, network connectedness measures how many pairs of nodes are tied by a network path of any length as a proportion of all pairs of nodes. Mathematically, connectedness can be defined as

$$
\text { connectedness }=\frac{\sum_{i=1}^{n} \sum_{j=1}^{n} r_{i j}}{n(n-1)},
$$

where $r_{i j}$ is defined as 1 if nodes $i$ and $j$ are connected by a path of any length and 0 otherwise (Borgatti et al. 2013:154). Connectedness can take on values ranging from 0 , when the network is composed of isolates, to 1 when all nodes can be reached from any node. Researchers sometimes prefer to present the complement of connectedness ( 1 - connectedness), also called fragmentation, to capture the proportion of pairs of nodes that cannot reach each other by a path of any length. In an occupational network, connectedness will tell us how many occupations can be eventually reached by workers starting in other occupations over multiple transitions. Fragmentation captures the extent to which a labor market is disconnected. ${ }^{5}$

Average geodesic distance. Another measure of network cohesion is the average geodesic distance between all connected pairs of nodes in a network. In an occupational network, the geodesic distance indicates the minimum amount of occupational transitions that a worker must experience to reach another particular occupation. The average of such minimum transitions is therefore a measure of how long it would take for a worker to move between two randomly chosen occupations, and hence how difficult or improbable such a journey would be. It is important to note that under this definition, all occupations that cannot be reached from a given occupation are excluded from the computation of the average distance. Thus, an occupational network with many disconnected occupations may actually have a low average distance if the remaining occupations are tightly connected. For this reason, average distance should be assessed along with other measures of connectivity, including connectedness.

\section{Occupational Status Mobility}

The measures of cohesion introduced in the previous section allow us to assess the extent to which workers can move to other occupations within the labor market. However, they do not provide information about whether workers are able to move up or down the social hierarchy of occupations. To distinguish occupational mobility along a scale of social status from the overall level of occupational mobility discussed in the previous section, we will refer to the former specifically as occupational status mobility. As discussed earlier, a large body of sociological research has been concerned with measuring the amount of occupational status mobility in the United States. Network analysis tools provide a nonparametric way of assessing occupational status mobility. By measuring the level of connectivity between lowand high-status occupations using several alternative techniques we can compare the amount of occupational movement along a status hierarchy at different points in time.

Any analysis of occupational status mobility necessarily requires us to distinguish which occupations are higher in status than others. In the analysis below 
we rely on Duncan's (1961) Socioeconomic Index (SEI) updated by Hauser and Warren (1997). Duncan's SEI is essentially a weighted average of the education and earnings of workers in each occupation (see the Data and Measurements section for details). In some of the analysis we will dichotomize occupations into those with high and low status. As discussed in the Data and Measurements section, we consider occupations in the top quartile of the SEI distribution to be of high status.

Between-and within-group density. A first approach for examining social mobility within an occupational network is to measure the density of ties between low- and high-status occupations. As defined earlier, the density of a valued network is the average probability that an occupational transition will occur in an occupational network. We may similarly calculate the density of ties from low- to high-status occupations and compare that with the density of ties from low- to low-status occupations. A higher density of ties from low- to high-status occupations indicates more upward mobility. ${ }^{6}$ The extent to which ties are concentrated among occupations of similar status also indicates the extent to which the labor market is segmented by status.

The density of ties between low and high occupational status groups computed using a valued occupational network will capture the total or gross mobility in the labor market at a particular point in time. ${ }^{7}$ Researchers examining intergenerational mobility, and to a lesser extent intragenerational mobility, have frequently chosen to distinguish structural mobility, which results from changes in the relative size of occupations of origin and destination over time, and relative mobility (or circulation or exchange mobility), which is the amount of mobility that exists beyond that attributed to changes in the size of occupations (Featherman and Hauser 1978; Jarvis and Song 2017; Torche 2015b). ${ }^{8}$ We analyze total mobility instead of relative mobility because we want to include the effect of structural changes (such as changes in technology and demographic shifts) that may result in differences in the size of occupations over time. However, the method proposed here could potentially be adapted to separate structural and relative occupational status mobility. ${ }^{9}$

Occupational mobility over multiple steps. The analysis of the density of ties between low- and high-status occupations only takes into account the status that individuals can achieve in a single occupational transition. Yet it may frequently take individual workers more than one transition to reach a high-status occupation. A more complete analysis of occupational status mobility should therefore consider the status achieved by workers over longer paths, which requires the use of information from the full network in which an occupation is embedded. We therefore also estimate the percentage of workers in low-status occupations who are able to reach a high-status occupation in successive number of steps (occupational transitions), as well as the average number of steps required to achieve a high-status occupation for individuals starting in a low-status occupation. A lower average number of steps necessary to reach a high-status occupation indicates greater upward mobility in the occupational network. ${ }^{10}$

Finally, an analysis of occupational status mobility that relies on a binary distinction between low- and high-status occupations may miss occupational transitions involving upward social mobility that do not surpass the required threshold. We therefore implement an alternative strategy that uses the entire range of occupa- 
tional status scores in which we calculate the maximum status workers can achieve in successive number of steps. The average of this measure for all workers in low-status occupations provides a succinct measure of mobility in the labor market at a particular point in time that does not depend on the use of a threshold for high-status occupations.

\section{Network Factions: Occupational Labor Market Segmentation}

The analysis of social mobility described above entails, among other things, assessing the extent to which the labor market is segmented by occupational status. In that analysis two occupational groups are specified, namely, those composed of occupations with low and high status, respectively. The density of ties (and therefore the amount of movement) within and between those two groups is then measured. A comparison of the density of ties within and between groups serves as a measure of segmentation along predefined lines. In the analysis below we will also explore the extent of labor market segmentation more generally without imposing a predefined metric for dividing the occupations into groups. The occupational network will first be divided into groups that best capture structural segments of the occupational labor market, and only afterwards do we assess whether these segments correspond to occupations of different status. Rather than imposing a division of occupations based on status, this exploratory analysis lets the data speak for themselves, as it were.

Various procedures have been developed to partition a social network into groups (for overviews and historical background, see Freeman [2011] and Wasserman and Faust [1994]:249-90). To study occupational segmentation, we specifically employ a form of factional analysis that divides the network into groups in which cohesion within groups is maximized and cohesion between groups is minimized (Borgatti et al. 2013). The resulting groups, called factions, represent clusters of occupations among which workers move relatively freely but from which workers are not easily able to move. We have chosen this technique for partitioning the occupational network because it corresponds closely with the definition of OILMs noted earlier.

Mathematically, factional analysis partitions the occupational contingency table into a block matrix that is as close as possible to having blocks of ones in the diagonal and blocks of zeroes off the diagonal. The specific algorithm used searches for a partition of nodes that minimizes the number of ties that need to be removed or added in order to have perfect cohesion within factions and no cohesion between factions. ${ }^{11}$ The algorithm will partition the network into any specified number of factions. Because the intragroup density will be larger and intergroup density lower when a larger number of factions are specified, we will explore results using a different number of factions.

\section{Data and Measurements}

Data for this study are extracted from the monthly panels of the CPS available through the Minnesota Population Center's Integrated Public Use Microdata Series 
(IPUMS) (Flood et al. 2018). The CPS has a rotating panel structure in which households are interviewed a total of eight times over 16 months. The first four interviews are in consecutive months. The household is then out of the sample for eight months and re-interviewed for an additional four consecutive months. Panels are staggered such that approximately one-eighth of the sample is in their first interview, one-eighth of the sample is in their second interview, and so on. We use information about respondents' occupation in consecutive waves to construct the occupational transition matrices. To make all the time intervals between waves equal to one month, we exclude transitions occurring between the fourth and fifth wave of every panel, which are spaced 9 months apart. ${ }^{12}$

Each cell in the occupational transition matrix $x_{i j}$ is calculated as the number of workers moving from occupation $i$ to occupation $j$ between consecutive months divided by the total number of workers in occupation $i$ in the initial month. In this way, $x_{i j}$ is an estimate of the probability that a worker in occupation $i$ will move to occupation $j$ in a given month. Longitudinal sampling weights provided by the CPS are used in these calculations (Drew, Flood, and Warren 2014). In order to increase the sample size, monthly occupational transitions from multiple years are appended. Specifically, we create matrices capturing all monthly transitions for five-year intervals: 1996 to 2000, 2006 to 2010, and 2012 to 2016 (hereafter referred to by their midpoints as 1998, 2008, and 2014). By comparing the characteristics of the occupational networks created with data from these three time periods, we are able to evaluate the changes in the structure of the occupational labor market over the past two decades. The specific years were also chosen to minimize changes in the coding of occupations within time periods and over time.

We use the same occupational classification system for all three time periods in order to allow comparisons of network characteristics over time. The occupational categories used by the CPS were revised by the U.S. Census Bureau during the past decades, specifically in the years 1992, 2003, and 2011. Fortunately, IPUMS has recoded respondents' occupations for all years in the study into the 1990 occupational categories using a crosswalk developed by the Bureau of Labor Statistics (Meyer and Osborne 2005). We use this consistent classification system with a few modifications. Specifically, some 1990 occupational categories were empty in later years because no occupations were recoded into those categories. In such cases, we aggregated those occupational categories with the most similar ones based on the ties they share with other occupations. For this purpose we first created an occupational transition matrix for all the three time periods combined. We then estimated the Euclidean distances between all occupational nodes and merged occupations that were entirely missing in some years with those with the shortest distances. ${ }^{13}$ The final classification system includes 311 occupational categories. For some of the analysis we also group these detailed categories into 74 broader occupational groups based on the Census's system of classification. ${ }^{14}$ Because these broader occupational groups are more likely to remain consistent over time they also further reduce the risk that differences across time periods may be due to changes in the classification of the same job.

Like all other analyses of occupational mobility, we rely on the coding of workers' occupations by the survey we use. The classification of occupations in employment 
surveys including the CPS has been shown to be subject to measurement error (Abraham and Spletzer 2009; Fisher and Houseworth 2013). Although we cannot rule out the effect of measurement error entirely, the risk is reduced by replicating our results using larger occupational groupings and by restricting network ties to occupational movements with a high probability of occurrence (see below). In addition, we benefit from the use of dependent interviewing by the CPS. Individual respondents are first asked whether they changed jobs since the previous interview, and their new occupation is only recorded if they changed jobs. Otherwise their previous occupation is carried over (Fisher and Houseworth 2013). This helps further ensure that changes in occupational codes are not simply the result of a reclassification of the same job.

Our primary occupational network is restricted to men ages 25 to 55 who are currently employed full time and are not serving in the military. We also compute separate transition matrices for subcategories of male workers based on their race, ethnicity and level of education: non-Hispanic white, non-Hispanic black, Hispanic, college-educated, and non-college-educated men. ${ }^{15}$ By analyzing separate transition matrices we are able to examine the occupational opportunities available to these different demographic groups. For example, some occupations, such as medical doctor, require a college degree and are therefore not available to individuals with lower levels of education. Similarly, differences in occupational opportunities for ethnoracial minorities may result in markedly different movement patterns and their relative absence from certain occupations.

As explained in the methodological section, our analysis is based on valued networks in which each cell in the transition matrix is the probability of a particular occupational transition, as well as on binary networks that capture whether a transition between two occupational categories occurs. We also construct binary occupational networks in which ties are restricted to only those that meet a minimum probability threshold in order to minimize the influence of very rare occupational transitions. We specifically report findings from binary networks in which occupational transitions are restricted to those with a monthly probability greater than 0.001 and 0.005 (i.e., transitions experienced by more than one and five workers per thousand employed in a particular occupation over the span of a month, respectively).

As noted earlier, our transition matrices normalize the flow of workers between two occupations by the number of workers in the sending occupation. Such normalization makes the results easier to interpret because each cell in the transition matrix, $x_{i j}$, becomes an estimate of the probability that a worker in occupation $i$ will move to occupation $j$. However, an analysis of such a matrix gives equal weight to the probability of moving from occupations of different sizes. Thus, the probability of moving from occupations with very few workers will be weighed as much as the probability of moving from occupations that account for a large share of the labor force. Estimates obtained using these transition matrices may not be representative for the average worker in the United States. In some of our analysis below we therefore weigh the probability of each transition by the total number of workers in the sending occupation (see Heitzig et al. [2012] and Zemp et al. [2014] for discussions of network analysis using nodal weights). 
Finally, for our analysis of occupational mobility we rely on a commonly used measure of occupational standing mentioned earlier: the SEI first proposed by Duncan (1961) and updated by Hauser and Warren (1997). The SEI is a weighted average of the education and earnings of workers in each occupation. It is computed by first regressing occupational prestige ratings on workers' education and earnings for a limited set of occupations and then using the results of these regressions to estimate the rating for all occupational categories (Hauser and Warren 1997). The index obtained from IPUMS is based on the 1990 occupational classification and remains the same for each occupation across all time periods. In analyses using a binary measure of occupational status we consider occupations in the top quartile of the SEI distribution to be of high status.

Whenever possible, statistical significance tests of the differences in network measures over time and across sociodemographic groups are conducted. Standard techniques for hypothesis testing are not appropriate for use with network data (Borgatti et al. 2013:125-48). Network ties originating or ending in particular nodes cannot be assumed to be independent observations, thus violating a key assumption of some tests. Also, because the nodes in the occupational network constitute the universe of all occupations in the U.S. labor market, significance tests used to draw inferences regarding dyadic relations from a population sample may not be meaningful. Nonparametric permutation tests are instead used to generate a distribution for the outcome of interest. To keep network properties the same for each permutation, entire rows and their corresponding columns in the network matrix are randomly rearranged using a method called the quadratic assignment procedure (Snijders and Borgatti 1999).

\section{Results}

Panels A and B of Figure 1 show the occupational networks for working-age men in 1998 and 2014, respectively. The nodes are labeled with the corresponding code for each occupation. The arrows in the network diagrams indicate the direction of each occupational transition. To simplify the visualization, the panels are constructed using the networks that restrict ties to those in which the monthly probability of an occupational transition is greater than 0.005 . Although patterns in the clustering of occupations are difficult to visualize even when restricting the network to ties with a relatively high probability of occurrence, we see a higher overall density of ties in 2014 compared with 1998. As discussed earlier, the greater density of ties in a binary network indicates a greater diversity in occupational mobility for workers over time. A close inspection of both panels reveals that a particular occupation with code 22 has a very large number of ties. This occupational code corresponds to managers "not elsewhere classified" and includes workers in a broad range of managerial positions. To gauge the influence that this single occupation may have on our estimates of network connectivity and occupational mobility, we estimate the density of the occupational networks with and without this occupation in the analysis below. ${ }^{16}$ 


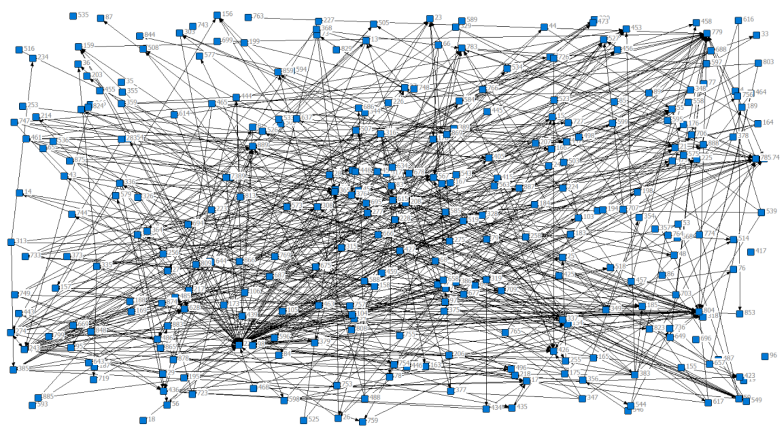

(a) Occupational network in 1998 .

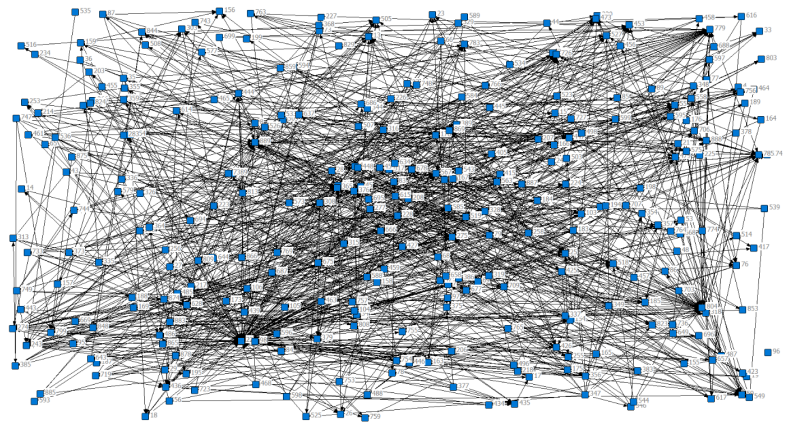

(b) Occupational network in 2014.

Figure 1: Occupational networks for all working men in 1998 and 2014 restricting ties to occupational transitions with monthly probabilities greater than 0.005 .

\section{Occupational Mobility and Connectivity}

Density. Table 1 presents estimates of the density of ties for the occupational networks for all male workers in the three time periods. The density is computed for the valued network, in which a tie between two occupations is equal to the probability that a worker in the first occupation will move to the second, and for the binary network in which ties are dichotomized. As noted earlier, the density of the valued network is a measure of occupational mobility, whereas the density of a binary network measures the occupational connectivity or diversity in occupational transitions. Table 1 also presents the network density for binary networks where ties are restricted to occupational transitions that exceed the two probability thresholds defined earlier. Categories within Table 1 show the network density for alternative specifications meant to establish the robustness of the observed trends in occupational mobility and connectivity. First, as described in the previous section, the network densities are computed for occupational networks in which each node is weighted by the total number of workers employed in the corresponding occupation. Second, to specifically assess the influence that the occupation consisting of managers and administrators not elsewhere classified (code 22) may have on the estimates of connectivity and mobility, network densities are also computed excluding this occupation from all calculations. Finally, network densities are also estimated using larger occupational groups to reduce the possibility that the observed trends are the result of changes in the classification of the same job over time.

The results uniformly indicate an increase in both occupational mobility and connectivity during the observed time period. The tests of statistical significance using the bootstrapping method described earlier confirm that the differences in network density in 2008 and 2014 relative to the baseline year of 1998 are statistically significant. For example, the densities for the full valued networks indicate that the average probability that a transition between any two occupations will occur is 58.6 percent higher in 2014 than in 1998. The differences are likewise significant when the binary occupational networks are used and when the network is restricted to 
Table 1: Network density for all men, 1998 to 2014.

\begin{tabular}{|c|c|c|c|}
\hline & 1998 & 2008 & 2014 \\
\hline \multicolumn{4}{|l|}{ Unweighted } \\
\hline Valued network $(\times 1,000)$ & 0.145 & $0.186^{\dagger}$ & $0.230^{\dagger}$ \\
\hline Binary network, full & 0.108 & $0.132^{\dagger}$ & $0.141^{\dagger}$ \\
\hline Binary network, $p>0.001$ & 0.036 & $0.044^{\dagger}$ & $0.052^{\dagger}$ \\
\hline Binary network, $p>0.005$ & 0.006 & 0.007 & $0.010^{\dagger}$ \\
\hline \multicolumn{4}{|l|}{ Weighted } \\
\hline Valued network $(\times 1,000)$ & 0.125 & $0.159^{\dagger}$ & $0.206^{\dagger}$ \\
\hline Binary network, full & 0.325 & 0.354 & 0.368 \\
\hline Binary network, $p>0.001$ & 0.027 & $0.036^{\dagger}$ & $0.046^{\dagger}$ \\
\hline Binary network, $p>0.005$ & 0.003 & 0.003 & $0.005^{\dagger}$ \\
\hline \multicolumn{4}{|l|}{ Without occupation code 22} \\
\hline Valued network $(\times 1,000)$ & 0.134 & $0.175^{\dagger}$ & $0.217^{\dagger}$ \\
\hline Binary network, full & 0.104 & $0.127^{\dagger}$ & $0.137^{\dagger}$ \\
\hline Binary network, $p>0.001$ & 0.034 & $0.042^{\dagger}$ & $0.050^{\dagger}$ \\
\hline Binary network, $p>0.005$ & 0.005 & 0.006 & $0.009^{\dagger}$ \\
\hline \multicolumn{4}{|l|}{ Occupational groups } \\
\hline Valued network $(\times 1,000)$ & 0.564 & $0.696^{\dagger}$ & $0.889^{\dagger}$ \\
\hline Binary network, full & 0.546 & $0.601^{\dagger}$ & $0.614^{\dagger}$ \\
\hline Binary network, $p>0.001$ & 0.155 & $0.190^{\dagger}$ & $0.223^{+}$ \\
\hline Binary network, $p>0.005$ & 0.018 & 0.022 & $0.036^{\dagger}$ \\
\hline
\end{tabular}

Notes: Significance tests relative to 1998 (see text for a description of how statistical tests are conducted). ${ }^{*} p<0.05,{ }^{\dagger} p<0.01$ (two-tailed tests).

ties reaching the two probability thresholds. Thus, the occupational networks in later years are characterized by both a greater overall mobility of workers across occupations and a greater diversity of occupational movements even when such movements are restricted to those that are more common. Weighing occupational nodes by the number of workers employed in each occupation results in lower estimates of network density in all years when the valued networks are used, and higher estimates when network ties are dichotomized. Yet even when nodal weights are used, we continue to observe an increase in occupational mobility and connectivity over time.

Panels A and B of Figure 2 show the network density for the full valued and binary occupational networks for workers of different race and ethnicity and level of education. The panels indicate an overall increase in occupational mobility and connectivity between occupations over the past two decades for all sociodemographic groups. More interestingly, the results also indicate large differences in network density for workers of different race and ethnicity and level of education. The occupational network density is higher for black and Hispanic workers than for white workers when the full valued network is used in Figure 2A (the differences are statistically significant). This finding suggests that black and Hispanic workers experience greater occupational mobility than white workers. However, when ties between occupations are dichotomized, black and Hispanic workers have a lower 


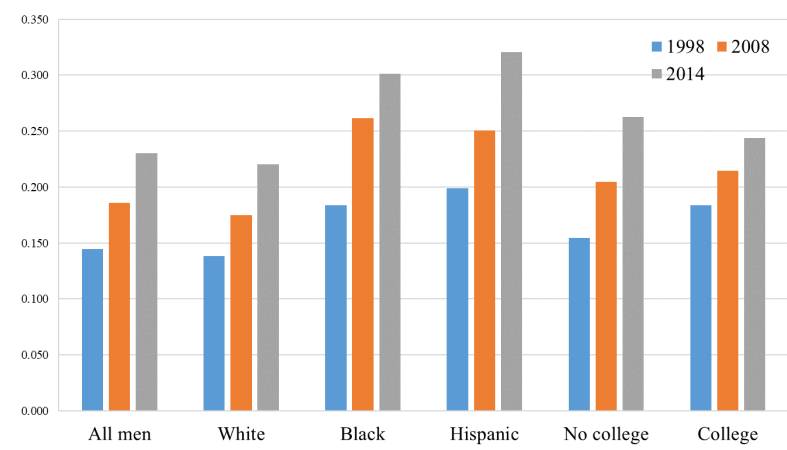

(a) Densities of valued occupational networks.

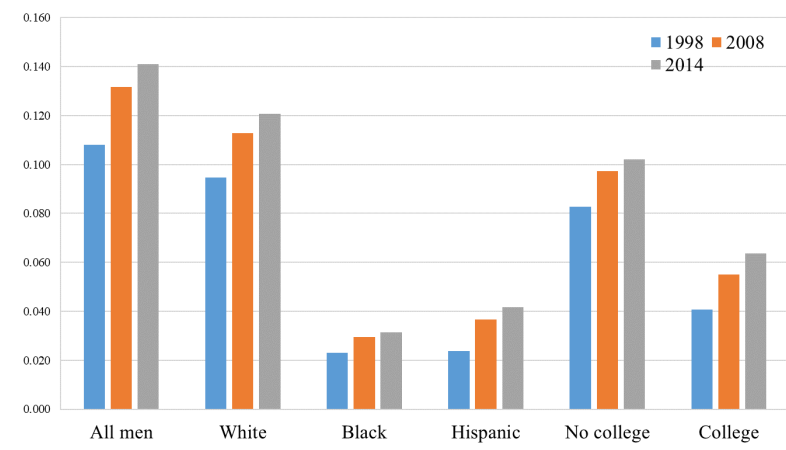

(b) Densities of binary occupational networks.

Figure 2: Densities of valued and full binary occupational networks for different sociodemographic groups, 1998 to 2014.

density of occupational ties (the differences are statistically significant). Thus, the greater density of ties for black and Hispanic workers in the valued network is explained by fewer occupational transitions with a very high probability of occurrence. Black and Hispanic workers appear to experience a high rate of movement between a limited set of occupations. ${ }^{17}$

Connectedness and average geodesic distance. As discussed earlier, estimates of network density do not take into account occupational transitions beyond those immediately available to workers in a particular occupation. Network density can be computed solely based on the direct ties that an occupation has with other occupations and therefore provides limited information about occupational mobility and connectivity in the labor market. By contrast, the indicators of network cohesion presented in Table 2 use information from the entire network in which occupations are embedded. They take into account the occupations that workers can reach over multiple transitions. Because these measures do not require information about the strength of ties between nodes, they are only computed using the binary networks.

As defined earlier, connectedness measures the proportion of all pairs of occupations that can be reached by a path of any length and is the complement of network fragmentation. The differences in connectedness are not evident in the full networks because they include all occupational transitions experienced by workers even if they are extremely rare. However, when the networks are restricted to transitions that workers can more realistically expect to experience, that is, those with a monthly probability of occurrence greater than 0.005 , we observe larger differences in connectedness. The connectedness of the networks limited to occupational transitions with a monthly probability of occurrence greater than 0.005 indicates that 3.8 percent of all possible paths between pairs of occupations were present in 2014, whereas only 1.1 percent of all such paths existed in 1998. Overall, the occupational labor market appears to have become significantly more connected, or conversely less fragmented, over time.

Table 2 also presents the average geodesic distance for all three time periods. As noted in the methodological section, the average geodesic distance tells us the 
Table 2: Network connectedness and average geodesic distance for all men, 1998 to 2014.

\begin{tabular}{lccc}
\hline & 1998 & 2008 & 2014 \\
\hline Binary network, full & & & \\
$\quad$ Connectedness & 0.984 & $1.000^{+}$ & 0.994 \\
$\quad$ Average distance & 2.002 & $1.950^{+}$ & $1.931^{+}$ \\
Binary network, $p>0.001$ & & & \\
$\quad$ Connectedness & 0.855 & $0.923^{+}$ & $0.946^{+}$ \\
$\quad$ Average distance & 3.494 & $3.270^{+}$ & $2.948^{\dagger}$ \\
Binary network, $p>0.005$ & & & \\
$\quad$ Connectedness & 0.011 & $0.016^{+}$ & $0.038^{+}$ \\
Average distance & 1.568 & $1.795^{+}$ & $2.404^{+}$ \\
\hline
\end{tabular}

Note: ${ }^{*} p<0.05,{ }^{\dagger} p<0.01$ (two-tailed test); comparisons with 1998 in all cases.

average minimum number of occupational transitions required for workers in one occupation to reach another for any pair of occupations that are connected. The results reveal an interesting pattern: When ties between occupations are not restricted or only restricted to those with a probability greater than 0.001 , the average distance decreased over time, indicating that workers need to traverse fewer occupations to reach their destinations (the differences are statistically significant). But when ties between occupations are restricted to more likely transitions with a monthly probability greater than 0.005 , the average geodesic distance significantly increases over time. Thus, although workers must experience fewer transitions to reach other occupations in 2014, many of these transitions are highly improbable. Once the analysis is limited to more realistic occupational transitions with a higher probability of occurrence, workers must traverse longer paths compared with workers in earlier time periods. Because geodesic distance calculations exclude nonexistent paths, we must interpret the average geodesic distance in combination with other measures such as connectedness, which indicate that workers in 2014 also reach a greater number of occupations. The average geodesic distance tells us that workers must traverse longer paths to reach those occupations.

Finally, panels A and B of Figure 3 show the connectedness of occupational networks restricted to male workers of different race and ethnicity and level of education. The top graph (Figure 3A) is based on estimates from the full binary network for each sociodemographic group in each time period, whereas the bottom graph (Figure 3B) is based on estimates from the networks restricted to occupational transitions with a monthly probability of occurrence greater than 0.005 . An interesting pattern emerges for men of different race and ethnicity: When the full occupational networks are used, black and Hispanic men have lower connectedness scores than white men every year, signaling lower occupational connectivity. But the opposite is true when the corresponding networks are restricted to ties with probabilities greater than 0.005 . This finding is consistent with the pattern observed for differences in density for the networks restricted by race and ethnicity noted earlier. In that figure we observed that the greater density of ties for black and Hispanic men in the full valued network was explained by fewer occupational transitions with a high probability of occurrence. 


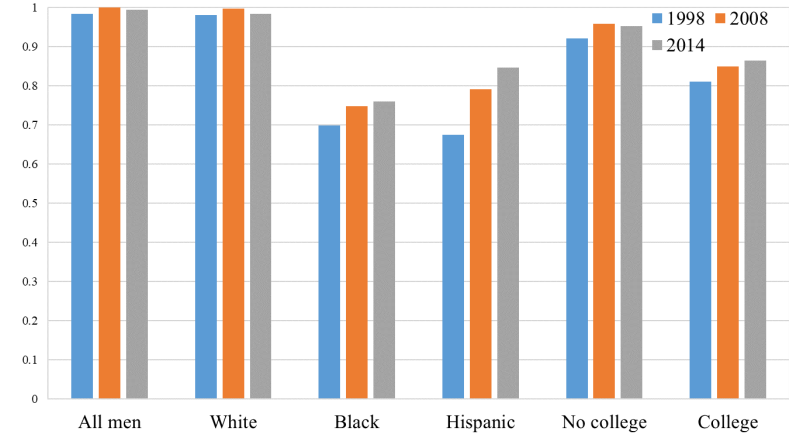

(a) Connectedness of full binary occupational networks.

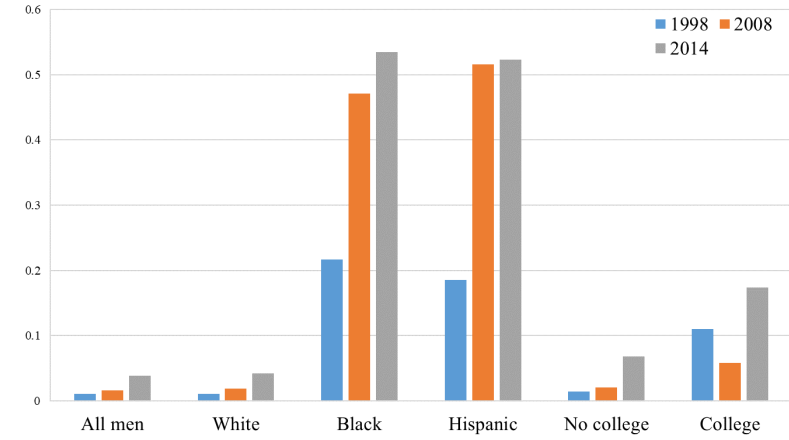

(b) Connectedness of binary occupational networks restricted to monthly probabilities greater than 0.005 .

Figure 3: Connectedness of full binary networks and networks restricted to ties with monthly probabilities greater than 0.005 for different sociodemographic groups, 1998 to 2014.

\section{Occupational Status Mobility}

So far we have examined the overall level of cohesion for occupational networks corresponding to several sociodemographic groups at different points in time. The results indicate the extent to which workers are able to move to other occupations within the labor market in general. All occupational transitions were treated equally regardless of the status of the occupation of origin and destination. However, as discussed in the theoretical section, network analysis tools can also help us assess the extent to which workers are experiencing upward social mobility within the occupational labor market.

Between- and within-group density. We begin our analysis of occupational status mobility by calculating the density of ties within and between low- and highstatus occupations. As discussed in the Data and Measurements section, highstatus occupations are defined using the top quartile of Hauser and Warren's socioeconomic index. The measures of density shown in Table 3 are similar to those for the entire occupational network discussed earlier except that nodes are separated into two categories and the density of ties within and between each category are calculated. The results are presented for the valued network as well as for the binary networks restricted to ties with different probabilities of occurrence. The analysis of occupational mobility is weighted by the number of workers in each occupation to make it representative of the average worker.

A clear pattern is evident in the densities within and between occupational status groups. First, the density of ties among nodes in the same category is always higher than the density of ties across categories. This means that workers in lowstatus occupations are more likely to move to other low-status occupations and workers in high-status occupations are more likely move to other higher-status ones. Second, the density of ties is much higher from high- to high-status occupations than from high- to low-status occupations, indicating that workers in high-status occupations tend to retain their high status following an occupational transition. 
Table 3: Density of ties between and within occupational status categories, 1998 to 2014.

\begin{tabular}{|c|c|c|c|c|c|c|c|c|c|}
\hline & & 1998 & & & 2008 & & & 2014 & \\
\hline \multicolumn{10}{|l|}{ Full valued network } \\
\hline & Low & High & Ratio & Low & High & Ratio & Low & High & Ratio \\
\hline Low & 0.142 & 0.102 & 0.72 & 0.183 & 0.127 & 0.70 & 0.235 & 0.173 & 0.74 \\
\hline High & 0.069 & 0.240 & 3.47 & 0.091 & 0.283 & 3.10 & 0.111 & 0.387 & 3.50 \\
\hline Odds ratio & & & 4.82 & & & 4.46 & & & 4.76 \\
\hline \multicolumn{10}{|l|}{ Full binary network } \\
\hline & Low & High & Ratio & Low & High & Ratio & Low & High & Ratio \\
\hline Low & 0.332 & 0.226 & 0.68 & 0.362 & 0.284 & 0.78 & 0.367 & 0.304 & 0.83 \\
\hline High & 0.331 & 0.472 & 1.43 & 0.337 & 0.500 & 1.48 & 0.355 & 0.538 & 1.52 \\
\hline Odds ratio & & & 2.09 & & & 1.89 & & & 1.83 \\
\hline \multicolumn{10}{|c|}{ Binary network, $p>0.001$} \\
\hline & Low & High & Ratio & Low & High & Ratio & Low & High & Ratio \\
\hline Low & 0.032 & 0.022 & 0.70 & 0.043 & 0.027 & 0.64 & 0.055 & 0.037 & 0.67 \\
\hline High & 0.014 & 0.046 & 3.36 & 0.020 & 0.059 & 2.93 & 0.024 & 0.081 & 3.35 \\
\hline Odds ratio & & & 4.80 & & & 4.57 & & & 4.99 \\
\hline \multicolumn{10}{|c|}{ Binary network, $p>0.005$} \\
\hline & Low & High & Ratio & Low & High & Ratio & Low & High & Ratio \\
\hline Low & 0.002 & 0.003 & 1.29 & 0.003 & 0.004 & 1.18 & 0.006 & 0.006 & 1.06 \\
\hline High & 0.000 & 0.011 & 23.73 & 0.001 & 0.011 & 22.07 & 0.001 & 0.017 & 29.21 \\
\hline Odds ratio & & & 18.40 & & & 18.64 & & & 27.63 \\
\hline
\end{tabular}

Note: Networks weighted by the total number of workers employed in each sending occupation.

This is highlighted by the ratio of the two measures presented in the last column of every panel. By contrast, the density of ties from low- to high-status occupations is generally lower than the density of ties from low- to low-status occupations. The corresponding ratio of densities for workers in low-status occupations in the full valued networks is an overall indicator of upward mobility in each time period. The ratio appears to be relatively stable from 1998 to 2014. Thus, according to this initial measure, the occupational status mobility of male workers has remained unchanged over the intervening years. The trend in occupational connectivity based on the ratio of densities for the binary networks is less clear: the ratio of densities for workers in low-status occupations increased over time for the full binary networks but decreased for the binary networks restricted to occupational transitions with a high probability of occurrence. This suggests that although the diversity of occupational movements from low- to high-status occupations increased overall, this greater diversity is based on occupational transitions that are uncommon.

To compare the patterns of upward occupational mobility for workers in lowstatus occupations of different sociodemographic backgrounds, we computed the corresponding ratio of the density of ties from low- to high-status occupations to the density of ties from low- to low-status occupations for male workers of different race and ethnicity, and educational attainment. The ratios shown in Figure 4 are computed using the full valued occupational networks. ${ }^{18}$ Clearly, workers with a college degree experienced greater occupational mobility than those without a 


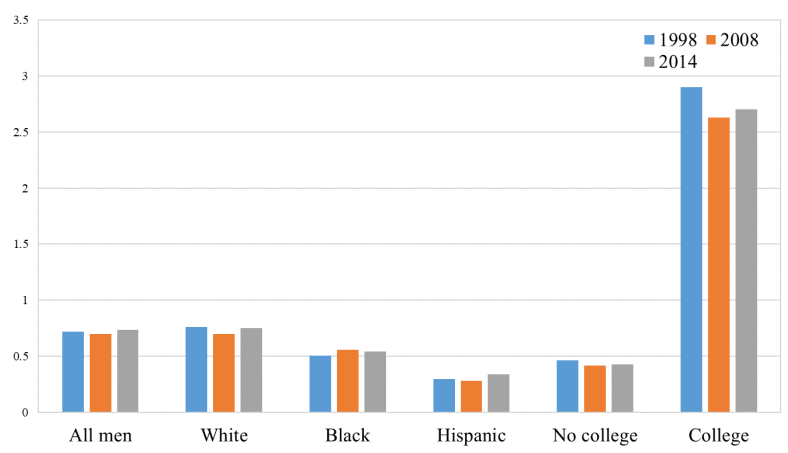

Figure 4: Ratio of density of ties between low-high and low-low occupational status occupations estimated using full valued networks for different sociodemographic groups, 1998 to 2014 (weighted).

college degree. Individuals with a college degree are generally underplaced for their education in low-status occupations. Moving to high-status occupations reflects their movement to occupations more commensurate with their level of education. The corresponding ratio of densities for workers of different race and ethnicity indicates lower upward mobility for black men, and even more so for Hispanic men relative to white men.

Occupational mobility over multiple steps. The densities presented in Table 3 and the corresponding ratios in Figure 4 provide useful information regarding workers' ability to reach high-status occupations in a single occupational transition. However, as discussed earlier, it may take workers more than one transition to reach a high-status occupation. To examine this possibility we calculate the percentage of workers in low-status occupations that can reach a high-status occupation in increasing number of steps (occupational transitions). We use the network restricted to transitions with monthly probabilities higher than 0.005 to eliminate transitions that are very rare. ${ }^{19}$ The results presented in the left panel in Table 4 reveal that workers in low-status occupations experienced a substantial increase in occupational status mobility over the past two decades. Whereas only 36.5 percent of workers in low-status occupations are able to reach a high-status occupation over multiple steps in 1998, 71.1 percent are able to do so in 2014. Workers in low-status occupations are more likely to achieve a high-status occupation in 2014 than in 1998 for the same number of occupational transitions.

The right panel in Table 4 shows the average maximum occupational status achieved by workers in low-status occupations in increasing number of steps. Instead of dichotomizing occupations into low- and high-status ones, these calculations use the entire range of occupational status scores to compute the average maximum status that workers in low-status occupations can achieve by number of transitions. The results again indicate an increase in occupational status mobility over time. Workers are able to reach occupations with an average status of 44.0 (out of a maximum of 81) in 2014, compared with only 36.4 and 37.5 in 1998 and 2008, respectively.

Panels A and B of Figure 5 show the percentage of workers in low-status occupations of different race and ethnicity and different levels of education who are 
Table 4: Percent achieving high occupational status and average maximum occupational status achieved in successive number of steps by workers in low-status occupations.

\begin{tabular}{lrrrrrr}
\hline & \multicolumn{3}{c}{$\begin{array}{c}\text { Percent achieving } \\
\text { high occupational status }\end{array}$} & \multicolumn{3}{c}{$\begin{array}{c}\text { Average maximum } \\
\text { occupational status achieved }\end{array}$} \\
\hline & 1998 & 2008 & 2014 & 1998 & 2008 & 2014 \\
\hline 0 step & 0.0 & 0.0 & 0.0 & 30.4 & 30.2 & 30.0 \\
1 step & 22.4 & 27.5 & 41.6 & 34.5 & 35.0 & 38.5 \\
2 steps & 35.4 & 42.3 & 56.5 & 36.2 & 37.2 & 41.4 \\
3 steps & 36.4 & 43.8 & 61.9 & 36.4 & 37.5 & 42.7 \\
4 steps & 36.5 & 43.9 & 67.7 & 36.4 & 37.5 & 43.6 \\
5 steps & & & 71.1 & & & 44.0 \\
All steps & 36.5 & 43.9 & 71.1 & 36.4 & 37.5 & 44.0 \\
\hline
\end{tabular}

Notes: Networks restricted to ties with monthly probabilities greater than 0.005 . Results weighted by the total number of workers employed in each sending occupation.

able to reach a high-status occupation in increasing number of steps in 1998. White workers are much more likely to reach high-status occupations and do so after fewer occupational transitions than black and Hispanic workers. After three occupational transitions, 35.5 percent of white workers who start off in a low-status occupation are able to reach a high-status occupation, compared with 30.6 percent of black workers and 31.2 percent of Hispanic workers. Similarly, more than 80 percent of college-educated male workers who start in a low-status occupation reach a high-status occupation within two occupational transitions, compared with less than 30 percent of non-college-educated male workers. Importantly, for all these categories of workers, the ability to reach a high-status occupation plateaus after three occupational transitions. Occupational advancement is extremely limited beyond three transitions. The analysis of occupational status mobility over multiple transitions illustrates the value of a network analysis approach. Our findings indicate that the differences in status mobility between workers of different race and ethnicity are even larger when multiple transitions are considered.

\section{Network Factions: Occupational Labor Market Segmentation}

As discussed earlier, factional analysis can be used to partition the occupational networks into groups that best capture structural segments of the labor market without using a particular metric for grouping occupations such as their SEI. Factional analysis allows us to identify clusters of occupations among which workers move relatively freely but across which workers are not easily able to move. The specific algorithm we use searches for a partition of nodes that minimizes the number of ties that need to be removed or added in order to have perfect cohesion within factions and no cohesion between factions (i.e., to create a perfect block matrix) ${ }^{20}$ To simplify the factional analysis, we first aggregate detailed occupational categories into the 74 broader occupational groups described in the Data and Measurements section. The network is restricted to occupational transitions with a monthly proba- 


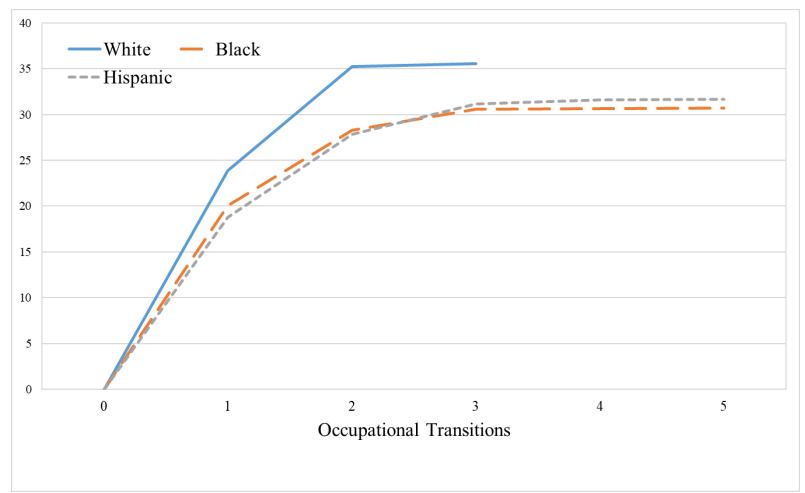

(a) By race and ethnicity.

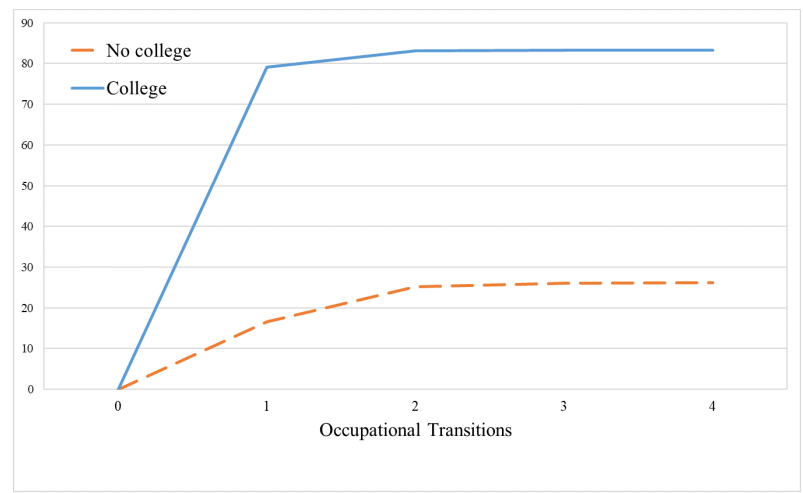

(b) By level of occupation.

Figure 5: Percent of workers in low-status occupations achieving high-status occupations by number of transitions estimated using networks restricted to ties with monthly probabilities greater than 0.005 (weighted), 1998.

bility of occurrence greater than 0.001 to eliminate occupational transitions that are rare. $^{21}$

Figure 6 shows the full occupational transition matrix for men in 1998. Cells shown in solid color represent existing ties between pairs of occupations. The three network factions identified by the factional analysis are delimited by solid lines. The density of ties is clearly much stronger among occupations belonging to the same factions than between occupations belonging to different factions. As noted earlier, the intragroup cohesion will be higher and intergroup cohesion lower as the number of factions increases. We therefore divided the occupational network into different number of factions. Table 5 shows the density of ties within and between factions when the occupational network is divided into two, three, and four factions each year. We observe a relatively segmented occupational labor market. For example, when we divide the occupational network in 1998 into two factions, we obtain a much higher density within the two factions $(0.22$ and 0.23 ) than between occupations belonging to different factions (0.08 and 0.09). As expected, the density within groups generally increases as we divide the network into a larger number of factions. Table 5 also reports two measures that can be used to assess whether occupational segmentation has increased over time. The first measure is the proportion of occupational ties that do not need to be changed to have perfect segmentation, that is, a situation in which all occupational transitions exist within factions but no transitions exist between factions. The second measure is the number of ties within factions as a proportion of all existing ties. By these measures, we see only a slight decrease in labor market segmentation from 1998 to 2014.

Table 6 reports the average occupational status for occupations belonging to each faction in 1998. Even though occupational status was not used as a criterion for separating network nodes into factions, we observe large differences in the average status of occupations belonging to different factions. For example, when dividing the occupational network into two factions, one faction includes all occupations 


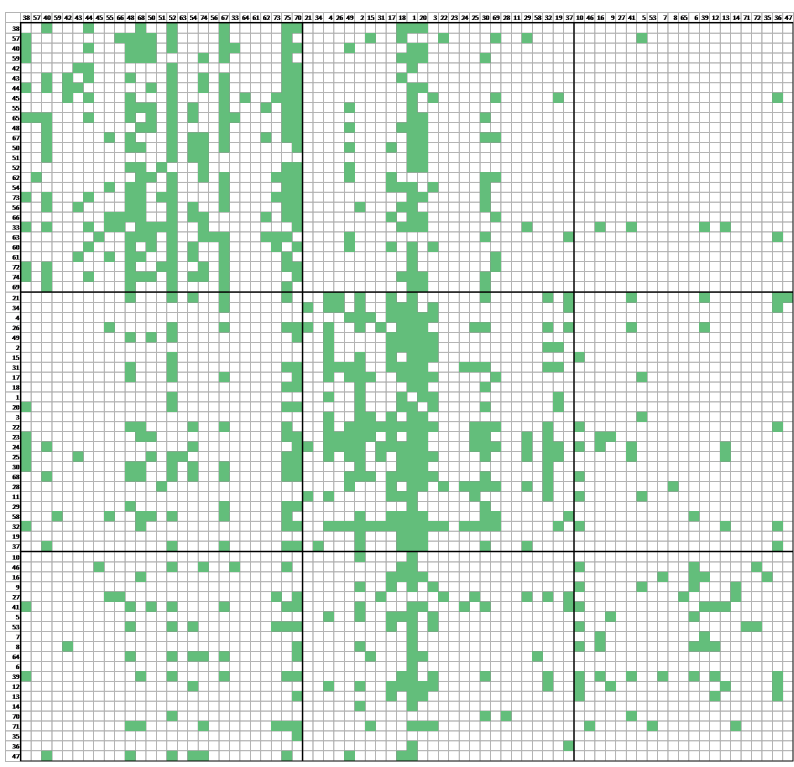

Figure 6: Block model of occupational network with three factions, 1998.

Table 5: Density of ties between and within network factions.

\begin{tabular}{|c|c|c|c|c|c|c|c|c|c|c|c|c|}
\hline & \multicolumn{4}{|c|}{1998} & \multicolumn{4}{|c|}{2008} & \multicolumn{4}{|c|}{2014} \\
\hline \multicolumn{13}{|c|}{ Two factions } \\
\hline & 1 & 2 & & & 1 & 2 & & & 1 & 2 & & \\
\hline 1 & 0.22 & 0.08 & & & 0.32 & 0.08 & & & 0.33 & 0.12 & & \\
\hline 2 & 0.09 & 0.23 & & & 0.14 & 0.22 & & & 0.14 & 0.31 & & \\
\hline \multicolumn{4}{|c|}{ Proportion correct } & 0.576 & & & & 0.587 & & & & 0.598 \\
\hline \multicolumn{4}{|c|}{ Proportion in diagonal } & 0.724 & & & & 0.711 & & & & 0.708 \\
\hline \multicolumn{13}{|c|}{ Three factions } \\
\hline & 1 & 2 & 3 & & 1 & 2 & 3 & & 1 & 2 & 3 & \\
\hline 1 & 0.33 & 0.12 & 0.01 & & 0.36 & 0.18 & 0.01 & & 0.49 & 0.03 & 0.13 & \\
\hline 2 & 0.13 & 0.35 & 0.05 & & 0.18 & 0.39 & 0.06 & & 0.25 & 0.12 & 0.15 & \\
\hline 3 & 0.09 & 0.13 & 0.11 & & 0.09 & 0.18 & 0.16 & & 0.22 & 0.04 & 0.40 & \\
\hline \multicolumn{4}{|c|}{ Proportion correct } & 0.703 & & & & 0.696 & & & & 0.701 \\
\hline \multicolumn{4}{|c|}{ Proportion in diagonal } & 0.600 & & & & 0.571 & & & & 0.578 \\
\hline \multicolumn{13}{|c|}{ Four factions } \\
\hline & 1 & 2 & 3 & 4 & 1 & 2 & 3 & 4 & 1 & 2 & 3 & 4 \\
\hline 1 & 0.42 & 0.03 & 0.14 & 0.01 & 0.50 & 0.04 & 0.01 & 0.15 & 0.53 & 0.05 & 0.22 & 0.01 \\
\hline 2 & 0.25 & 0.12 & 0.16 & 0.02 & 0.32 & 0.12 & 0.02 & 0.13 & 0.30 & 0.14 & 0.21 & 0.03 \\
\hline 3 & 0.15 & 0.03 & 0.42 & 0.06 & 0.12 & 0.01 & 0.25 & 0.19 & 0.25 & 0.04 & 0.51 & 0.07 \\
\hline 4 & 0.10 & 0.03 & 0.14 & 0.16 & 0.27 & 0.01 & 0.07 & 0.40 & 0.10 & 0.01 & 0.31 & 0.28 \\
\hline \multicolumn{4}{|c|}{ Proportion correct } & 0.760 & & & & 0.750 & & & & 0.745 \\
\hline \multicolumn{4}{|c|}{ Proportion in diagonal } & 0.502 & & & & 0.510 & & & & 0.500 \\
\hline
\end{tabular}

Note: Networks restricted to ties with monthly probabilities greater than 0.001 using grouped occupational categories.

with high status (those in the top quartile), whereas the other includes none. A similar pattern is observed when dividing the network into three and four factions. The results of the factional analysis therefore show not only that the occupational labor market is highly segmented into clusters of occupations across which work- 
Table 6: Average occupational status for network factions, 1998.

\begin{tabular}{lrrrr}
\hline & Faction 1 & Faction 2 & Faction 3 & Faction 4 \\
\hline Two factions & & & & \\
$\quad$ Average occupational status & 26.83 & 45.73 & & \\
$\quad$ Percent high status & 0.00 & 45.95 & & \\
Three factions & & & & \\
$\quad$ Average occupational status & 24.74 & 39.64 & 46.96 & \\
$\quad$ Percent high status & 0.00 & 30.77 & 42.86 & \\
Four factions & & & & \\
$\quad$ Average occupational status & 23.96 & 32.53 & 42.27 & 48.87 \\
$\quad$ Percent high status & 0.00 & 0.00 & 42.86 & 50.00 \\
\hline
\end{tabular}

Note: Networks restricted to ties with monthly probabilities greater than 0.001 using grouped occupational categories.

ers cannot easily move but also that these clusters correspond to occupations of markedly different status.

\section{Conclusions}

In this article we have proposed a new set of tools to examine the patterns of movement in occupational labor markets. Our application of techniques originally developed for the analysis of social networks provided new insights regarding the occupational mobility and labor market segmentation of U.S. workers over the past two decades. Our findings can be organized into three parts corresponding to sections of our empirical analysis. First, our exploration of network cohesion revealed a significant increase in occupational mobility and in the diversity of occupational destinations for working men in each of our ethnoracial groups and educational categories. We observed the increase in occupational mobility and connectivity both when we examined single occupational shifts and when we considered longer chains involving multiple transitions. A comparison of the average geodesic distance, which measures the minimum number of occupational transitions required to reach other occupations, revealed that workers needed to experience fewer transitions to reach other occupational destinations in recent years. However, these occupational transitions were relatively rare and often did not exceed the 0.005 monthly probability threshold. We also found important differences in occupational mobility for men of different race and ethnicity. The occupational networks for black and Hispanic workers exhibited a lower level of connectivity compared with white workers when all network ties were included but substantially higher connectivity when ties were restricted to only those with a high probability of occurrence. Our findings suggest that black and Hispanic workers experience a high rate of movement between a limited set of occupations.

Second, our analysis of changes in occupational status showed an overall increase in upward mobility for male workers over the three time periods analyzed. This trend was not apparent in our analysis of the density of ties between high- and 
low-status occupations. But when the change in the status of workers who start off in low-status occupations was examined over multiple transitions, we found that they were much more likely to reach high-status occupations in 2014 than in 1998. Whereas only 37 percent of low-status workers could reach a high-status occupation over multiple high-probability transitions in 1998, 71 percent could do so in 2014. The analysis also demonstrated significant differences in occupational status mobility by race and ethnicity, and even more so by level of education. Black and Hispanic men, and men without a college education were found to experience lower probabilities of reaching a high-status occupation even after many occupational transitions. Our analysis of occupational status mobility over multiple transitions illustrates the value of a network analysis approach. Our findings indicate that the differences in status mobility between workers of different race and ethnicity are even larger when multiple transitions are considered.

Third, our factional analysis revealed a highly segmented occupational labor market in which movement is concentrated within a limited number of occupational groups. The results indicated that 75 percent of all high-probability occupational transitions occur within four occupational factions, whereas the remaining 25 percent involved occupational transitions across these factions. Our factional analysis grouped occupations based solely on the underlying structure of ties rather than by imposing a predefined metric for dividing occupations into groups such as their occupational status. Nevertheless, we found large differences in the status of occupations belonging to different factions. Two of the four factions in 1998 included no occupations in the top quartile of occupational status. The high occupational labor market segmentation also appears to be remarkably persistent over time. We found no evidence of a significant change in the factionalization of occupational networks over the span of the two decades studied.

The occupational factions we identified may be said to resemble OILMs. Like OILMs, network factions are groups of occupations among which workers move relatively freely, but across which they rarely move. Of course, we cannot establish that the lack of movement across occupational factions is the result of practices of social closure that limit workers' ability to move. The lack of movement across occupational factions may also be the result of incentives provided by differences in pay and status. As other researchers have noted, OILMs are difficult to identify empirically (e.g., Althauser 1989). Our approach provides a concrete way to measure and compare the extent of labor market segmentation over time. Further research is required to investigate the reasons for this segmentation. A wide array of network analysis techniques have been developed for grouping network nodes, each one with distinctive properties (e.g., cliques, n-clans, k-plexes, k-cores, etc.) (see Wasserman and Faust 1994:249-90). Modularity-based partitioning techniques have also recently emerged as a popular approach for dividing networks (Newman 2006). Future research should also explore the utility of these alternative techniques for measuring labor market segmentation.

An important advantage of the network analysis approach we are proposing is that it can be implemented with readily available data from rotating panel surveys such as the CPS. Data from the monthly panels allowed us to construct highly detailed transition matrices that provide snapshots of the occupational labor market 
structure at different points in time. However, an underlying assumption of this approach is that all individuals are exposed to the same structural limitations and incentives. We have investigated differences in the occupational movements of individuals belonging to different sociodemographic groups by constructing separate transition matrices for each group. Further dividing workers into smaller sociodemographic categories would require appending even more years of survey data or using larger occupational groupings in order to have a sufficient number of cases in each occupational category.

Appending several years of data to create occupational transition matrices as we have done assumes that the pattern of transitions is relatively stable within a given time period. Our analysis involving multiple occupational transitions further assumes that individuals are exposed to the same transition matrix (and hence the same set of limitations and incentives to occupational movement) over time. Because some of the later occupational transitions may occur several years in the future, this assumption may not always be warranted. Our results nevertheless provide valuable information regarding the opportunities available to workers based on conditions at a given point in time. Our analysis is not unique in making projections based on current conditions. For example, demographic calculations of period life expectancies assume individuals are exposed to the present mortality rates in the future (Preston, Heuveline, and Guillot 2001:42-44). Similarly, the computation of total period fertility rates assume women experience the current age-specific fertility rates throughout their lifetimes (Preston, Heuveline, and Guillot 2001:93-99). Following the terminology used in demographic analysis, we may refer to estimates of mobility over multiple steps obtained using a transition matrix for a specific set of years as period mobility to distinguish it from the mobility of specific cohorts.

Our analysis has relied on information regarding changes in workers' occupations over relatively short time periods. Specifically, we examine job transitions over successive months of the CPS. We are, of course, not the first ones to use short-term job transition data to analyze occupational mobility in a labor market (e.g., Kim 2013). Previous research examining patterns of intragenerational mobility over short time periods has relied on log-linear methods to analyze contingency tables. Although some of the analyses conducted in this article can be performed by adapting log-linear methods, the network analysis approach we are proposing provides some benefits. Log-linear models often impose a particular structure to the pattern of occupational mobility based on assumptions about how workers move in the labor market that may not always be warranted (Sakamoto and Wang 2019). By contrast, network analysis techniques provide an intuitive, nonparametric way of examining occupational mobility. Second, network analysis methods make it easier to uncover new aspects of labor markets, such as the diversity in occupational mobility, and to compare patterns of mobility across multiple transitions. Third, the application of network analysis procedures for detecting substructures or groups allows us to explore patterns of occupational labor market segmentation. Finally, network analysis provides new ways of visualizing entire occupational networks and creating summary measures to compare labor markets over time and place. 
As in all other studies examining occupational mobility, our analysis depends on the consistency and accuracy with which occupations are coded. The classification of occupations in employment surveys including the CPS has been shown to be subject to measurement error (Abraham and Spletzer 2009; Fisher and Houseworth 2013; Kambourov and Manovskii 2008). Because our analysis relies on monthly changes in occupational codes, it may be particularly sensitive to inconsistencies in the coding of occupations over time. Changes in occupational codes from one month to the next may be the result of changes in the classification of the same job over time rather than an actual change in occupation. As noted earlier, the use of dependent interviewing by the CPS partly reduces this risk. CPS respondents are first asked whether they changed jobs since the previous interview, and their new occupation is only recorded if they changed jobs. Otherwise the previous occupation is carried over (Fisher and Houseworth 2013). Two additional features of our analysis further reduce the possibility that our findings are the result of misclassification of individuals' occupations. First, our analyses restrict occupational transitions to those that meet a minimum probability threshold (i.e., transitions experienced by more than one or five workers per thousand employed in a particular occupation). Errors in the classification of individuals' occupation are unlikely to result in flows of workers large enough to exceed these probability thresholds. Second, our results were replicated using broader occupational categories in which similar detailed occupations were grouped into larger ones. Errors consisting in the misclassification of individuals' occupations in similar ones or resulting from the conversion of occupational codes over time are substantially reduced when using these aggregate categories. Nevertheless, the risk of measurement error remains.

\section{Notes}

1 The matrix $X$ is therefore not symmetric ( $x i j \neq x j i$, in general, for every $i \neq j$ ).

2 Our analysis is therefore limited to workers who move between occupations. However, the analytical approach we propose could potentially be extended to include workers who stay in their occupations in consecutive time periods by allowing self-ties.

3 The average probability that a worker will change occupations is equal to the density of a valued occupational network multiplied by $n-1$. An alternative measure of cohesion, known as the average out-degree, is in fact equal to the probability that a worker will change occupations (density $\times[n-1]$ ). The average out-degree provides similar information as network density and is therefore not presented here. However, because out-degree can be computed at the nodal level rather than only for the network as a whole, it allows us to examine the distribution of ties across the entire occupational network. See the online supplement for a detailed examination of the out-degree distribution in the occupational networks for different sociodemographic groups over time.

4 As discussed below, an analysis of occupational mobility over multiple steps assumes that the occupational network is relatively stable over time. Following the terminology used in demographic analysis, we may refer to estimates of mobility over multiple steps obtained using a transition matrix for a specific set of years as period mobility to distinguish it from the mobility of specific cohorts.

5 An alternative measure, called compactness, incorporates information about the path length by weighing each path connecting a pair of nodes by the inverse of the number of 
required steps. Estimates of compactness show substantively similar patterns as those for compactness presented below but are omitted to conserve space.

6 The average probability of moving from a low- to a high-status occupation will be equal to the density of ties between the two occupational status groups multiplied by the number of high-status occupations. Because the number of high-status occupations is fixed for all years, the density is simply the average probability of upward mobility rescaled and is comparable across all three time periods.

7 As noted below, the analysis is weighted by the size of the occupation of origin to make the analysis representative of workers currently in the labor market.

8 For critiques of the distinction between structural and relative mobility, see Sakamoto and Wang (2019) and Sobel (1983).

9 To analyze changes in structural and relative occupational status mobility over time instead of total mobility, separate occupational networks may be computed by decomposing each tie in the valued network into the value expected based simply on the marginal totals and the remaining value. The density of ties from low- to high-status occupations using the remaining values as ties provides an estimate of mobility holding marginals constant. One complication with this approach is that it will generate negative values for some network ties when analyzing relative status mobility, but most network analysis software can handle negative ties. Our objective is to illustrate the potential of a network analysis approach to examine occupational status mobility. A decomposition of occupational status mobility into it structural and relative components is beyond the scope of this article.

10 The analysis we are proposing here does not estimate the actual probability of occupational changes involving multiple transitions. We only assess whether a path between the occupation of origin and destination exists and how many separate transitions it entails. Estimating the probability of occupational changes over multiple steps by repeatedly multiplying the same transition matrix assumes that occupational mobility behaves like a first-order Markov process. Early research demonstrated that social mobility does not quite conform to a Markov process and that repeatedly multiplying a stationary transition matrix results in inaccurate estimates of long-term mobility (see Blumen, Kogan and McCarthy [1955]; Hodge [1966]; McFarland [1970]; Singer and Spilerman [1973]).

11 The algorithm minimizes the Hamming distance. Another possible procedure for optimization consists in maximizing the correlation between the actual network and a block matrix with blocks of ones in the diagonal and blocks of zeroes off the diagonals.

12 Our research design requires us to match individual respondents across waves of the CPS, which is a difficult task. Fortunately, the CPS files available through IPUMS provide unique identification codes allowing researchers to easily match cases from month to month. Drew et al. (2014) outline in great detail the process used by IPUMS to match cases. They also provide summary statistics of the number of cases lost due to nonmatches and incorrect matches. They estimate an overall attrition rate of approximately 5 percent when matching individuals eligible to be interviewed in two consecutive months of the CPS. Drew et al. (2014) report that "less than 1\% of mechanically linked records [across months of the CPS] are mismatched on age, sex, and/or race" (Pp. 131-32). This attrition rate compares favorably to other sources used to follow individuals' labor market trajectories such as the Survey of Income and Program Participation (U.S. Census Bureau 1998).

13 This approach for handling occupational codes that are missing in some years is preferable to merging them with occupations that appear to be substantively similar insofar 
as it is expected to cause the least impact on the properties of the overall occupational matrix.

14 For the grouping of occupational categories, see the documentation available in the IPUMS website: https://usa.ipums.org/usa/volii/occ1990.shtml.

15 Female workers are excluded from the sample because they are likely to experience different constraints in their occupational mobility. A breakdown of women by race and ethnicity and level of education would result in an insufficient number of workers in each occupation to make the detailed transition matrices stable for the specified years.

16 Mouw and Kalleberg (2010) note that this same occupational category is disproportionately implicated in the rise of wage inequality.

17 See the online supplement for an exploration of the distribution of nodal out-degree for the different occupational networks. Nodal out-degree provides additional information regarding mobility and connectivity in the occupational labor market.

18 Results for the full binary occupational network and the binary occupational networks in which ties are restricted to those with a monthly probability of occurrence greater than 0.001 and 0.005 are similar to those presented in Figure 4.

19 As noted in the results for connectedness presented earlier, using occupational networks that include low probability transitions is not very informative because such networks result in near saturation conditions in which most occupations are reachable from any other occupation (connectedness values are close to 1.0). Differences in connectedness become more evident when the networks are restricted to monthly probabilities greater than 0.005 .

20 The algorithm does not produce a single solution for a specified number of factions. Different initial partitions were used to corroborate that the results presented were robust.

21 Because multiple occupations are grouped together, restricting the monthly probability of a transition between these more aggregated occupational categories is not the same as restricting transitions between the more detailed occupational categories to the same probability threshold. Results using networks restricted to occupational transitions with a monthly probability of occurrence greater than 0.005 are substantively similar to those presented here.

\section{References}

Abraham, Katharine G., and James R. Spletzer. 2009. “New Evidence on the Returns to Job Skills." American Economic Review 99(2):52-57. https ://doi .org/10.1257/aer .99. 2.52.

Althauser, Robert P. 1989. “Internal Labor Markets." Annual Review of Sociology 15:143-161. https://doi.org/10.1146/annurev.so.15.080189.001043.

Althauser, Robert P., and Arne L. Kalleberg. 1981. "Firms, Occupations, and the Structure of Labor Markets." Pp. 119-49 in Sociological Perspectives on Labor Markets, edited by Ivar Berg. New York: Academic Press.

Baldi, Stéphane, and Debra Branch McBrier. 1997. "Do the Determinants of Promotion Differ for Blacks and Whites? Evidence from the U.S. Labor Market." Work and Occupations 24(4):478-97. https://doi.org/10.1177/0730888497024004005.

Blau, Peter M., and Otis Dudley Duncan. 1967. The American Occupational Structure. New York: Free Press. 
Blumen, Isadore, Marvin Kogan, and Philip J. McCarthy. 1955. The Industrial Mobility of Labor as a Probability Process. Ithaca, NY: Cornell University Press.

Borgatti, Stephen P., Martin G. Everett, and Jeffrey C. Johnson. 2013. Analyzing Social Networks. Los Angeles: Sage Publications.

Breen, Richard, and Jan O. Jonsson. 2005. "Inequality in Opportunity in Comparative Perspective: Recent Research on Educational Attainment and Social Mobility." Annual Review of Sociology 31:223-43. https : //doi .org/10.1146/annurev . soc . 31 . 041304. 122232.

DiPrete, Thomas A., and K. Lynn Nonnemaker. 1997. "Structural Change, Labor Market Turbulence, and Labor Market Outcomes." American Sociological Review 62(3):386-404. https://doi.org/10.2307/2657312.

Doeringer, Peter B., and Michael J. Piore. 1971. Internal Labor Markets and Manpower Analysis. New York: M. E. Heath.

Drew, Julia A. Rivera, Sarah Flood, and John Robert Warren. 2014. “Making Full Use of the Longitudinal Design of the Current Population Survey: Methods for Linking Records across 16 Months." Journal of Economic and Social Measurement 39(3):121-44. https : //doi .org/10.3233/JEM-140388.

Duncan, Otis Dudley. 1961. “A Socioeconomic Index for All Occupations.” Pp. 109-38 in Occupations and Social Status, edited by Albert J. Reiss, Jr. New York: Free Press.

Erikson, Robert, and John H. Goldthorpe. 1992. The Constant Flux: A Study of Class Mobility in Industrial Societies. New York: Oxford University Press.

Featherman, David L., and Robert M. Hauser. 1978. Opportunity and Change. New York: Academic Press.

Fisher, Jonathan D., and Christina A. Houseworth. 2013. "Occupation Inflation in the Current Population Survey." Journal of Economic and Social Measurement 38(3):243-61. https://doi .org/10.3233/JEM-130377.

Flood, Sarah, Miriam King, Renae Rodgers, Steven Ruggles, and J. Robert Warren. 2018. "Integrated Public Use Microdata Series, Current Population Survey: Version 6.0" [data set]. Minneapolis, MN: Integrated Public Use Microdata Series. https ://doi .org/10. 18128/D030.V6.0.

Freeman, Linton C. 2011. "The Development of Social Network Analysis - with an Emphasis on Recent Events." Pp. 26-39 in The SAGE Handbook of Social Network Analysis, edited by John Scott and Peter J. Carrington. Thousand Oaks, CA: Sage. https://doi .org/10. 4135/9781446294413.n3.

Fuller, Sylvia. 2008. "Job Mobility and Wage Trajectories for Men and Women in the United States." American Sociological Review 73(1):158-83. https ://doi .org/10.1177/ 000312240807300108.

Gerber, Theodore P. 2002. "Structural Change and Post-Socialist Stratification: Labor Market Transitions in Contemporary Russia." American Sociological Review 67(5):629-59. https : //doi.org/10.2307/3088910.

Grusky, David B., and Jesper B. Sørensen. 1998. "Can Class Analysis Be Salvaged?" American Journal of Sociology 103(5):1187-234. https : //doi .org/10 .1086/231351.

Hauser, Robert M. 1978. "A Structural Model of the Mobility Table." Social Forces 56(3):919-53. https://doi.org/10.2307/2577226.

Hauser, Robert M., and John Robert Warren. 1997. "Socioeconomic Indexes for Occupations: A Review, Update, and Critique." Sociological Methodology 27(1):177-298. https ://doi. org/10.1111/1467-9531.271028. 
Heitzig, J., J. F. Donges, Y. Zou, N. Marwan, and J. Kurths. 2012. “Node-Weighted Measures for Complex Networks with Spatially Embedded, Sampled, or Differently Sized Nodes." European Physical Journal B 85(38):1-22. https: //doi .org/10.1140/epjb/e2011-206787.

Hodge, Robert W. 1966. “Occupational Mobility as a Probability Process." Demography 3(1):19-34. https://doi.org/10.2307/2060061.

Hollister, Matissa N. 2012. "Employer and Occupational Instability in Two Cohorts of the National Longitudinal Surveys." Sociological Quarterly 53(2):238-63. https : //doi .org/ 10.1111/j.1533-8525.2012.01233.x.

Hout, Michael. 1983. Mobility Tables. Thousand Oaks, CA: Sage Publications. https : //doi.org/10.4135/9781412985086.

Instituto Nacional de Estadística, Geografía e Informática (INEGI). 2005. Encuesta Nacional de Ocupación y Empleo 2005. Mexico: INEGI.

Jarvis, Benjamin F., and Xi Song. 2017. “Rising Intragenerational Occupational Mobility in the United States, 1969 to 2011." American Sociological Review 82(3):568-99. https : //doi.org/10.1177/0003122417706391.

Jonsson, Jan O., David B. Grusky, Matthew Di Carlo, Reinhard Pollak, and Mary C. Brinton. 2009. "Microclass Mobility: Social Reproduction in Four Countries." American Journal of Sociology 114(4):977-1036. https : //doi .org/10.1086/596566.

Kalleberg, Arne L., and Ted Mouw. 2018. “Occupations, Organizations, and Intragenerational Career Mobility." Annual Review of Sociology 44:283-303. https ://doi.org/10.1146/ annurev-soc-073117-041249.

Kambourov, Gueorgui, and Iourii Manovskii. 2008. "Rising Occupational and Industry Mobility in the United States: 1968-97." International Economic Review 49(1):41-79. https : //doi.org/10.1111/j.1468-2354.2008.00473.x.

Kambourov, Gueorgui, and Iourii Manovskii. 2009. “Occupational Specificity of Human Capital." International Economic Review 50(1):63-115. https://doi.org/10.1111/j . 1468-2354.2008.00524.x.

Kim, Young-Mi. 2013. “Diverging Top and Converging Bottom: Labour Flexibilization and Changes in Career Mobility in the USA." Work, Employment and Society 27(5):860-79. https://doi.org/10.1177/0950017012464418.

Kronberg, Anne-Kathrin. 2013. "Stay or Leave? Externalization of Job Mobility and the Effect on the U.S. Gender Earnings." Social Forces 91(4):1117-46. https://doi .org/10.1093/ sf/sot041.

Kwon, Illoong, and Eva M. Meyersson Milgrom. 2014. "The Significance of Firm and Occupation Specific Human Capital for Hiring and Promotions." Labour Economics 31:162-73. https://doi.org/10.1016/j. labeco.2014.07.003.

Longhi, Simonetta, and Malcolm Brynin. 2010. “Occupational Change in Britain and Germany." Labour Economics 17(4):655-66. https ://doi .org/10.1016/j . labeco. 2010.02. 001.

Manzoni, Anna, Ruud Luijkx, and Ruud Muffels. 2011. “Explaining Differences in Labour Market Transitions between Panel and Life-Course Data in West-Germany." Quality and Quantity 45:241-61. https://doi.org/10.1007/s11135-009-9292-1.

McFarland, David D. 1970. "Intragenerational Social Mobility as a Markov Process: Including a Time-Stationary Markovian Model That Explains Observed Declines in Mobility Rates over Time." American Sociological Review 35(3):463-76. https ://doi .org/10.2307/ 2092989. 
Meyer, Peter B., and Anastasiya M. Osborne. 2005. "Proposed Category System for 19602000 Census Occupations." Working Paper No. 383, U.S. Bureau of Labor Statistics. https://usa.ipums.org/usa/resources/chapter4/OCCBLS_paper.pdf.

Moody, James, and Jonathan Coleman. 2015. "Clustering and Cohesion in Networks: Concepts and Measures." Pp. 906-912 in International Encyclopedia of the Social \& Behavioral Sciences, edited by James D. Wright. Amsterdam: Elsevier. https://doi .org/10.1016/ B978-0-08-097086-8.43112-0.

Moscarini, Giuseppe, and Francis G. Vella. 2008. “Occupational Mobility and the Business Cycle." Working Paper No. 13819, National Bureau of Economic Research. https: //doi.org/10.3386/w13819.

Mouw, Ted, and Arne L. Kalleberg. 2010. "Occupations and the Structure of Wage Inequality in the United States, 1980s to 2000s." American Sociological Review 75(3):402-31. https : //doi.org/10.1177/0003122410363564.

Newman, M. E. J. 2006. "Modularity and Community Structure in Networks." Proceedings of the National Academy of Sciences 103(23):8577-82. https://doi .org/10.1073/pnas . 0601602103.

Office for National Statistics. 2019. "Labour Force Survey - User Guidance." UK Office for National Statistics. Retrieved May 3, 2019, https : //www . ons . gov . uk/employmentandlabourmarket/peopleinwork/employmentandemployeetypes / methodologies/labourforcesurveyuserguidance.

Parrado, Emilio A. 2005. "Economic Restructuring and Intra-Generational Class Mobility in Mexico." Social Forces 84(2):733-57. https : //doi .org/10.1353/sof . 2006. 0026.

Parrado, Eric, Asena Caner, and Edward N. Wolff. 2007. “Occupational and Industrial Mobility in the United States." Labour Economics 14(3):435-55. https ://doi .org/10. 1016/j.labeco.2006.01.005.

Petersen, Trond, and Laurie A. Morgan. 1995. "Separate and Unequal: OccupationEstablishment Sex Segregation and the Gender Wage Gap." American Journal of Sociology 101(2):329-65. https://doi.org/10.1086/230727.

Pomer, Marshall I. 1986. "Labor Market Structure, Intragenerational Mobility, and Discrimination: Black MaleAdvancement Out of Low-Paying Occupations, 1962-1973." American Sociological Review 51(5):650-59. https://doi .org/10.2307/2095490.

Preston, Samuel H., Patrick Heuveline, and Michel Guillot. 2001. Demography: Measuring and Modeling Population Processes. Malden, MA: Blackwell Publishers.

Rosenfeld, Rachel A. 1980. "Race and Sex Differences in Career Dynamics." American Sociological Review 45(4):583-609. https : / /doi .org/10.2307/2095010.

Rosenfeld, Rachel A. 1992. "Job Mobility and Career Processes." Annual Review of Sociology 18:39-61. https://doi.org/10.1146/annurev.so.18.080192.000351.

Sakamoto, Arthur, and Sharron Xuanren Wang. 2019. “The Declining Significance of Occupational Contingency Tables in the Study of Intergenerational Mobility." Paper presented at the 2019 Annual Meeting of the Population Association of America, April 10, Austin, TX.

Shaw, Kathryn L. 1987. “Occupational Change, Employer Change, and the Transferability of Skills." Southern Economic Journal 53(3):702-19. https ://doi .org/10.2307/1058765.

Shin, Taek-Jin. 2007. "The Impact of Structural Dynamics on Job Mobility Rates in the United States." Social Science Research 36(4):1301-27. https : //doi .org/10.1016/j . ssresearch . 2007.03 .001$.

Singer, Burton, and Seymour Spilerman. 1973. "Social Mobility Models for Heterogeneous Populations." Sociological Methodology 5:356-401. https ://doi .org/10.2307/270841. 
Snijders, Tom A.B., and Stephen P. Borgatti. 1999. "Non-Parametric Standard Errors and Tests for Network Statistics." Connections 22(2):161-70.

Sobel, Michael E. 1983. "Structural Mobility, Circulation Mobility and the Analysis of Occupational Mobility: A Conceptual Mismatch." American Sociological Review 48(5):72127. https://doi.org/10.2307/2094930.

Sørensen, Aage B. 1975. "The Structure of Intragenerational Mobility." American Sociological Review 40(4):456-71. https : //doi . org/10.2307/2094433.

Sørensen, Jesper B., and David B. Grusky. 1996. “The Structure of Career Mobility in Microscopic Perspective." Pp. 83-114 in Social Differentiation and Social Inequality: Essays in Honor of John Pock, edited by James N. Baron, David B. Grusky, and Donald J. Treiman. Boulder, CO: Westview Press.

Statistics Canada. 2009. Guide to the Labour Force Survey, 2009. Catalogue no. 71-543-G. Ottawa: Statistics Canada, 2009. Retrieved May 3, 2019, http://www.statcan.gc.ca/ pub/71-543-g/71-543-g2009001-eng.pdf.

Stier, Haya, and David B. Grusky. 1990. “An Overlapping Persistence Model of Career Mobility." American Sociological Review 55(5):736-56. https : //doi . org/10. 2307/2095869.

Stolzenberg, Ross M. 1975. “Occupations, Labor Markets and the Process of Wage Attainment." American Sociological Review 40(5):645-65. https : //doi .org/10 . 2307/2094200.

Sullivan, Paul. 2010. "Empirical Evidence on Occupation and Industry Specific Human Capital." Labour Economics 17(3):567-80. https://doi .org/10.1016/j . labeco. 2009. 11.003.

Tomaskovic-Devey, Donald. 1993. Gender and Race Inequality at Work. Ithaca, NY: ILR Press.

Torche, Florencia. 2015a. "Intergenerational Mobility and Equality of Opportunity." European Journal of Sociology 56(3):343-71. https : //doi .org/10.1017/S0003975615000181.

Torche, Florencia. 2015b. "Analyses of Intergenerational Mobility: An Interdisciplinary Review." The Annals of the American Academy of Political and Social Science 657(1):37-62. https://doi .org/10.1177/0002716214547476.

U.S. Census Bureau. 1998. “SIPP Quality Profile 1998." Survey of Income and Program Participation (SIPP) Working Paper No. 230. Washington: U.S. Department of Commerce, Bureau of the Census.

Wasserman, Stanley, and Katherine Faust. 1994. Social Network Analysis: Methods and Applications. Cambridge: Cambridge University Press. https ://doi .org/10.1017/ CB09780511815478.

Weeden, Kim A. 2002. "Why Do Some Occupations Pay More than Others? Social Closure and Earnings Inequality in the United States." American Journal of Sociology 108(1):55-101. https://doi.org/10.1086/344121.

Weeden, Kim A., and David B. Grusky. 2005. "The Case for a New Class Map." https : //doi .org/10.1086/428815.American Journal of Sociology 111(1):141-212. https://doi . org/10.1086/428815.

Wilson, George, and Vincent J. Roscigno. 2010. "Race and Downward Mobility from Privileged Occupations: African American/White Dynamics across the Early Work-Career." Social Science Research 39(1):67-77. https : //doi .org/10.1016/j . ssresearch. 2009.03. 008.

Yu, Wei-hsin. 2010. "Enduring an Economic Crisis: The Effect of Macroeconomic Shocks on Intragenerational Mobility in Japan." Social Science Research 39(6):1088-107. https : //doi.org/10.1016/j.ssresearch.2010.04.003. 
Zemp, D. C., M. Wiedermann, J. Kurths, A. Rammig, and J. F. Donges. 2014. "NodeWeighted Measures for Complex Networks with Directed and Weighted Edges for Studying Continental Moisture Recycling." Europhysics Letters 107(5):1-6. https : //doi.org/10.1209/0295-5075/107/58005.

Zhou, Xueguang, Nancy Brandon Tuma, and Phyllis Moen. 1997. "Institutional Change and Job-Shift Patterns in Urban China, 1949 to 1994." American Sociological Review 62(3):339-65. https://doi.org/10.2307/2657310.

Andrés Villarreal: Department of Sociology, University of Maryland-College Park.

E-mail: avilla4@umd.edu. 